References

Faculty of Family Planning and Reproductive Health Care Clinical Effectiveness Unit. FFPRHC Guidance (April J Fam Plann Reprod Health Care 2005; 31: 139-150. Faculty of Family Planning and Reproductive Health $\mathrm{C}$ Clinical Effectiveness Unit. FFPRHC Guidance (April 2003). Emergency contraception. J Fam Plann Reprod Health Care 2003; 29(2): 9-16.

\section{Editor's Note: Missed pill correspondence}

Interested readers may wish to note that there has been a letter ${ }^{1}$ from the Clinical Effectiveness Unit (CEU) published in the Lancet, in response to the April Editorial $^{2}$ by Diana Mansour and Ian Fraser.

The main points of this letter can be summarised as follows: The authors believe that most women know the name and type of their pill and would be able to apply the recommendations. They believe having different rules for 20 and $30 \mu \mathrm{g}$ ethinylestradiol pills minimises intervention and inconvenience for the maximum number of women. They state a pill has been missed only when 24 hours have elapsed after the scheduled time. They did not review the three studies cited by Mansour and Fraser as suggesting caution about extending the pill-free interval beyond 7 days; two were published after the World Health Organization recommendations were developed. Finally, the Faculty of Family Planning and Reproductive Health Care's philosophy is to be guided by evidence, not fear of litigation.

A comment in response to the letter has been placed on the Lancet's website. ${ }^{3}$ For our readers' convenience, we have permission to reproduce it in full below.

1 Penney G, Brechin S, Glasier A, Bigrigg A. Missed S. 1264. DOI: 10.1016/S0140-6736(05)67522-8.

Mansour D, Fraser IS. Missed contraceptive pills and the critical pill-free interval. Lancet 2005; 365: 1670-1671. http://www.thelancet.com/journals/lancet/article/ PIIS0140673605675228/comments?action=view\&totalCo mments $=1$.

\section{Comment on Lancet website: Missed pill guidelines \\ Dear $\mathrm{Si}$}

In the same week that the Faculty of Family Planning's Clinical Effectiveness Unit (CEU) stated that "we assume that most women know the name and type of their pill", ${ }^{1}$ a paper in the Journal of Family Planning and Reproductive Health Care showed that $41 \%$ of a group of educated women were not even sure whether they were taking a high- or a low-dose pill. ${ }^{2}$ In the same issue of that Journal, Thurrock Primary Care Trust explained that they felt they could not use the new guidelines in their area because their clients "would have difficulty following the new advice". 3

There have been letters to that Journal pointing out the deficiencies of the CEU's guidelines on missed pills, over the last 6 months, yet the widespread concerns are simply being ignored by the Faculty. Is it a valid excuse to say that papers that suggest their guidelines are unsafe were published after the WHO recommendations? Why did the CEU not take those findings into account when considering important new guidelines?

Competing Interests: None.

Barbara Hollingworth, DRCOG, FFFP

Consultant and Lead Clinician in Family Planning and Reproductive Health, Redbridge and Havering PCTs, Essex, UK

Caroline Marfleet, MB BS, FFFP

Consultant in Family Planning and Reproductive Health, Colchester General Hospital, Turner Road, Colchester CO4 5LJ, UK
Elphis Christopher, MIPM, FFFP

Consultant in Family Planning and Reproductive Health, Haringey PCT, London, UK

Ruth M Clancy, MIPM, MFFP

Consultant in Family Planning, Sutton and Merton PCT, Surrey, UK

Gillian Robinson, FRCOG, MFFP

Associate Specialist in Sexual and Reproductive Health, Southwark PCT, London, UK

1 Penney G, Brechin S, Glasier A, Bigrigg A. Missed contraceptive pill recommendations. Lancet 2005; 366:

van der Westhuizen M, Hall D. Are affluent, well-educated, career-orientated women knowledgeable users of the oral contraceptive pill?. J Fam Plann Reprod Health Care 2005;

Willis C, Whitwell I. Missed pill guidelines (Letter). J Fam

Interested readers should refer to the Lancet's website for any further responses or comments.

\section{DMPA and BMD}

Following the Committee on Safety of Medicines (CSM) advice for prescribers of depot medroxyprogesterone acetate (DMPA) in November 2004, there has been continued discussion regarding its effects on bone mineral density (BMD), and what this may mean long term for bone health and fracture risk.

To examine women's views and knowledge regarding this issue we produced a short anonymous questionnaire for women using DMPA who attend contraception and sexual health clinics in Newcastle-upon-Tyne. It was given to all women prior to their consultation appointment at three clinics between January and June 2005.

All 64 patients to whom the questionnaire was given completed it, and their ages ranged from 17 to 46 (mean, 25.8) years. They had been using DMPA for between 3 months and 9 years (mean duration of use, 2.6 years).

Of these patients, $53(83 \%)$ were aware of the possible effects of DMPA on BMD, and all of these women felt that their concerns had been discussed. Four of these patients (all in their twenties) were considering a change of contraception following reading about the CSM advice in the media or as a result of discussing this issue with a health care professional. One woman was definitely going to change her method of contraception to a progestogen-only implant.

Those women who were not considering a change to their contraception (i.e. $90.5 \%$ of those aware of the link with reduced BMD) cited various reasons for continuing DMPA including:

- the potential reversibility of BMD changes

- researching the topic themselves and finding the evidence weak

- belief that they were not at risk of osteoporosis

- worrying about forgetting pills

- concern related to side effects with other forms of contraception.

There were 11 patients who stated that they were not aware of any effects DMPA may have on bone health. This was $17 \%$ of the sample, which is rather concerning. All the patients said they had been given a Family Planning Association leaflet on injectables before or at the start of DMPA use, which highlights the importance of ensuring patient understanding within the consultation rather than relying on written information which may not be read, understood or retained. All the women in this group had the effects of DMPA on BMD discussed with them after completion of the questionnaire and all decided to continue using this method of contraception.

As health professionals, it is easy to presume that women attending for repeat prescriptions are aware of issues regarding their contraceptive method. However, patient choice can only be informed if it is based on current evidence, even if this involves sharing uncertainty regarding guidance.

From this small audit only one woman planned to change her contraceptive method from DMPA, although four others were considering a change ( $8 \%$ of the total). We do not know, however, how many women have chosen to start other birth control methods in the light of this information or those who have discontinued DMPA and are now using less effective methods. Overall DMPA still remains a popular choice for women wanting a highly effective yet reversible method of contraception, and the majority of established users surveyed wish to continue its use.

Ruth Parry, MB BS, MRCGP

VTS Registrar, Graingerville Clinic, Newcastle Contraception and Sexual Health Service, Newcastle General Hospital, Newcastle-uponTyne, UK

Diana Mansour, FRCOG, FFFP

Consultant in Community Gynaecology and Reproductive Health Care, Graingerville Clinic, Newcastle Contraception and Sexual Health Service, Newcastle General Hospital, Westgate Road, Newcastle-upon-Tyne NE4 6BE, UK.

E-mail:diana.mansour@newcastle-pct.nhs.uk

\section{Audit of documentation of female}

\section{sterilisation}

We read with great interest the paper by Anderson et al. on documentation of preoperative counseling for female sterilisation: a complete audit cycle ${ }^{1}$ in which the authors have provided evidence on the usefulness of a standardised proforma in the documentation of counselling women requesting sterilisation. Their documentation was fully compliant with the Royal College of Obstetricians and Gynaecologist (RCOG)'s guidelines ${ }^{2}$ only when a standardised proforma was used during the counselling.

A recently completed re-audit of documentation of female sterilisation carried out in our department has identified areas where there is room for further improvement in our practice. It is our experience that the awareness of the standards set out in the RCOG's guidelines was not enough on its own to facilitate changes towards improving the quality of communication and to ensure that our documentation process was fully compliant with the RCOG's guidelines.

Sterilisation is a major cause of litigation involving gynaecological practice, accounting for $25 \%$ of all claims notified to the Medical Defence Union. ${ }^{3}$ In order to minimise the risk of litigation, the need for adequate documentation and the use of a checklist as an important part of informed consent procedures was identified in a previous study. ${ }^{4}$

The present authors have now demonstrated that the introduction of a standardised proforma can significantly improve the level of compliance with the RCOG's guidelines by improving the quality of documentation.

If our ultimate goal is to improve the quality of care and thereby reduce the high level of complaints and litigation associated with female sterilisation, then the available evidence would suggest that units providing the female sterilisation service should seriously consider the use of a standardised proforma that would ensure that a consistent and adequate information as recommended by the RCOG is provided to all patients requesting sterilisation.

Deeba Yunus, MB BS

Senior House Officer, Edith Watson Unit, Burnley General Hospital, Casterton Avenue, Burnley BB10 2PQ, UK 